\title{
Acute kidney injury following on-pump or off-pump coronary artery bypass grafting in elderly patients: a retrospective propensity score matching analysis
}

Rui Wang ${ }^{1 *+}$, Xian Wang ${ }^{2+}$, Yifan Zhu' ${ }^{1}$, Wen Chen ${ }^{1}$, Liangpeng Li $^{1}$ and Xin Chen ${ }^{1 *}$

\begin{abstract}
Objectives: This single-centre, retrospective propensity score matching (PSM) study designed to study the impact of cardiopulmonary bypass (CPB) on postoperative acute kidney injury (AKI) and the relationship between AKI and long-term outcomes in elderly patients undergoing coronary artery bypass grafting (CABG).

Methods: After PSM, 466 pairs of patients (A group, on-pump; B group, off-pump) who were aged $\geq 70$ years undergoing first isolated CABG surgery from January 2012 to December 2016 entered the study. AKI was defined and classified according to the Acute Kidney Injury Network (AKIN) criteria. The incidence and severity of in-hospital AKI were compared. The impacts of AKI on the long-term outcomes including new onset of dialysis and mortality were analyzed.

Results: The two PSM groups had similar baseline and procedure except whether the CPB was used or not. In hospital and 30-day mortality was of no difference $(X 2=0.051, p=0.821)$. AKI of any severity occurred in $40.3 \%$ of all patients, with stage 1 accounting for most cases. No difference regarding the incidence and severity of AKI could be found: AKIN stage 1: 139 (29.8\%) vs 131 (28.1\%); AKIN stage 2: 40 (8.6\%) vs 35 (7.5\%); AKIN stage 3: 18 (3.9\%) vs $13(2.8 \%),(u=0.543, p=0.532)$. No difference was observed in the in-hospital new onset of dialysis $(X 2=0.312, P=$ 0.576). The use of CPB was not found to influence long-term new onset of dialysis ( $x 2=0.14, p=0.708$ ) and mortality $(X 2=0.099, p=0.753)$. Comparing with non-AKI patients, AKI patients were associated with an increased rates of new onset of dialysis $(x 2=8.153, p=0.004)$ and mortality $(x 2=6.277, p=0.012)$ during the follow-up. Multivariable logistic regression manifested that the HR for long-term new onset of dialysis and mortality in AKI patients vs. non-AKI patients was 1.83 and 1.31 respectively $(95 \% \mathrm{Cl} 1.12-2.86, p=0.007 ; 95 \% \mathrm{Cl} 1.17-2.58, p=0.015)$. The HR for long-term new onset of dialysis and mortality in on-pump group vs. off-pump group was 1.07 and 1.11 respectively $(95 \% \mathrm{Cl} 1.03-1.23, p=0.661 ; 95 \% \mathrm{Cl} 1.09-1.64, p=0.702)$.

(Continued on next page)
\end{abstract}

\footnotetext{
* Correspondence: wr1582@163.com; stevecx@njmu.edu.cn

${ }^{\dagger}$ Rui Wang and Xian Wang contributed equally to this work.

'Department of Cardiovascular Surgery, Nanjing First Hospital, Nanjing

Medical University, Nanjing, 68 Changle Rd, Nanjing 210006, People's

Republic of China

Full list of author information is available at the end of the article
}

(c) The Author(s). 2020 Open Access This article is licensed under a Creative Commons Attribution 4.0 International License, which permits use, sharing, adaptation, distribution and reproduction in any medium or format, as long as you give appropriate credit to the original author(s) and the source, provide a link to the Creative Commons licence, and indicate if changes were made. The images or other third party material in this article are included in the article's Creative Commons licence, unless indicated otherwise in a credit line to the material. If material is not included in the article's Creative Commons licence and your intended use is not permitted by statutory regulation or exceeds the permitted use, you will need to obtain permission directly from the copyright holder. To view a copy of this licence, visit http://creativecommons.org/licenses/by/4.0/ The Creative Commons Public Domain Dedication waiver (http://creativecommons.org/publicdomain/zero/1.0/) applies to the data made available in this article, unless otherwise stated in a credit line to the data. 


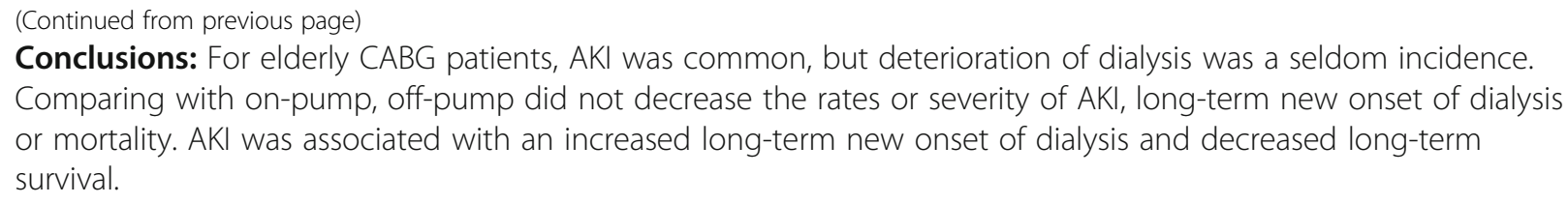

Keywords: Acute kidney injury, Coronary artery bypass grafting, Elderly, Cardiopulmonary, Glomerular filtration rate, Long-term survival

\section{Background}

Acute kidney injury (AKI) is a sudden loss of kidney function defined by an acute increase in serum creatinine concentration and decrease in urinary output [1]. Up to $30 \%$ of patients with varying severity develop AKI after coronary artery bypass grafting (CABG) surgery, and approximately $2 \%$ require temporary dialysis [2]. Postoperative AKI is associated with increased short and long term morbidity and mortality $[3,4]$.

Based on the presence of cardiopulmonary bypass (CPB) or not, $C A B G$ could be divided into on-pump CABG and off-pump CABG. It is generally accepted that $\mathrm{CPB}$ is a risk factor for AKI after CABG because that $\mathrm{CPB}$ is associated with inflammatory response, nonpulsatile flow, hemodilution, renal hypoperfusion, atheroembolism, and free hemoglobin $[5,6]$. However, whether off-pump technique could improve the outcome of CABG is still a controversial issue, and many studies have compared outcomes between on-pump and offpump technique. In general, there is a higher proportion of AKI in the on-pump group than in the off-pump group, $[7,8]$ but no significant differences with regard to the outcomes of mortality and renal failure $[7,9,10]$. These results manifested that postoperative AKI in the on-pump CABG did not translate to adverse outcomes, which conflicted with results from the literature conducted previously. Furthermore, age is another risk factor for AKI, but studies focused on the elderly(aged $\geq 70$ years) patients who are especially vulnerable to AKI undergoing CABG are relatively rare.

The purpose of this study was to study AKI in elderly patients undergoing first isolated CABG performed with either on-pump or off-pump technique through a single centre, retrospective propensity score matching(PSM) study. Compared with on-pump, we speculated offpump CABG might reduce the incidence and magnitude of AKI in vulnerable elderly patients, and if correct, aimed to obverse if there was a difference in long-term kidney function and survival.

\section{Methods}

\section{Definition of renal function}

The glomerular filtration rate (GFR) was calculated by the abbreviated Modification of Diet in Renal Disease equation:186 $\times(\text { serum creatinine } / 88.4)^{-1.154} \times(\text { age })^{-0.203} \times$ (0.742 if female). Kidney function before CABG was graded from I to $\mathrm{V}$ according to the GFR as proposed by the Kidney Disease Outcome Quality Initiative [11]. Patients with preexisting stage $\mathrm{V}$ (end-stage kidney failure with a GFR below 15 or renal replacement) were excluded, and patients suffered from any nephrotoxicity were also excluded from further analysis postoperatively.

AKI was defined and classified according to the criteria proposed by the Acute Kidney Injury Network $(\mathrm{AKIN})$ as AKIN stage 1: increase creatinine $\times 1.5$ from baseline or increase of $>0.3 \mathrm{mg} / \mathrm{dL}$ within $48 \mathrm{~h}$; AKIN stage 2: increase creatinine $\times 2$ from baseline; and AKIN stage 3: increase in creatinine $\times 3$ from baseline or creatinine $>4 \mathrm{mg} / \mathrm{dL}$ with an acute increase $>0.5 \mathrm{mg} / \mathrm{dL}$ within $48 \mathrm{~h}$ or new-onset of dialysis therapy [12].

\section{Study population}

A standard set of perioperative data was collected prospectively for all patients undergoing first isolated CABG at Nanjing First Hospital between January 2012 to December 2016. Clinical data were retrospectively collected from Jiangsu Province CABG registry study database. The register website is: http://221.226.218.114:1 0004/Multicenter. Patients undergoing a concomitant cardiac surgical procedure, reoperation, urgent or emergent operation, minimal invasive operation, or with incomplete information were excluded. This study was approved by The Ethics Committee of Nanjing First Hospital. All patients agreed that their stored material was enclosed and that their clinical data were anonymously used for statistical analysis.

All CABG surgeries were performed by the experienced surgeons. On-pump CABG was performed via median sternotomy using a membrane oxygenator equipped with an arterial filter, cold blood antegrade cardioplegia under moderate systemic hypothermia (30$34^{\circ} \mathrm{C}$ ); hematocrit was maintained about $20-22 \%$ during CPB. Off-pump CABG was performed with a stabilizator and an intra-coronary shunt.

Totally there were 1358 cases up to the standard for analysis. To control the selection bias in the comparison among on-pump group and off-pump group, a propensity score (PS) analysis was performed. One PS was 
calculated for each patient by means of logisticregression analysis using 16 preoperative and surgical variables including: age, gender, body mass index(BMI), diabetes mellitus(DM), hypertension, hyperlipemia, GFR, chronic obstructive pulmonary disease(COPD), history of cerebral and myocardial infarction(MI), history of percutaneous coronary intervention(PCI), left ventricular ejection fraction(LVEF), number of vessel disease, EuroSCOREII, number of distal anastomosis, the application of left internal mammary artery(LIMA) and radial artery. Every on-pump CABG patient was matched with an offpump CABG patient with the closest PS (within0.030). Finally, 466 pairs were successfully built in a 1:1 manner through matching PS [A group (on-pump, $n=466$ ) and B group (off-pump, $n=466$ )].

\section{Statistical analysis}

Data are represented as the mean \pm standard deviation unless otherwise indicated. Categorical variables are represented as frequency distributions and single percentages. Normally distributed continuous variables were compared using a Student t-test, non-normally distributed continuous variables using the Mann-Whitney $U$ test, and categorical variables were compared by $\chi^{2}$ test. Potential risk factors were calculated by Cox regression analysis. Potential independent predictors of outcome were identified by univariate Cox regression analysis. All statistical tests were two-sided. A $p$-value of less than 0.05 was considered significant. All statistical analyses were done with IBM SPSS Statistics 20.0 or STATA Data analysis and statistical software.

\section{Results}

\section{Matching of patients}

Matching data from A group $(n=466)$ and B group $(n=$ 466) were analyzed. There were no significant differences with regard to age, gender, BMI, DM, hypertension, hyperlipemia, GFR, COPD, history of cerebral and MI, history of PCI, LVEF, number of vessel disease, Euro-SCOREII, number of distal anastomosis including LIMA and radial artery. (Table 1).

\section{In-hospital outcomes}

A total of 20 patients died after the operation (11 in A group and 9 in B group, $p=0.821$ ). There were no significant differences with regard to in-hospital mortality, MI, stroke, respiratory failure, pneumonia, AKI, inhospital dialysis, RBC transfusion, deep sternal wound infection (DSWI), low cardiac output syndrome(LCOS), intra-aortic balloon pump(IABP) support. AKI of any severity occurred in $40.3 \%$ patients totally (197 in A group and 179 in B group), with AKIN stage 1 accounting for most of the AKI cases(71.8\%).No significant difference
Table 1 Baseline and procedural characteristics after matching

\begin{tabular}{|c|c|c|c|}
\hline \multirow[t]{2}{*}{ variable } & \multirow{2}{*}{$\begin{array}{l}\text { A group } \\
(n=466) \\
\text { No. }(\%)\end{array}$} & B group & \multirow[t]{2}{*}{$p$ value } \\
\hline & & $\begin{array}{l}(n=466) \\
\text { No. }(\%)\end{array}$ & \\
\hline Female gender & $84(18.0)$ & $89(19.1)$ & 0.736 \\
\hline Age, y & $73.2 \pm 7.2$ & $74.0 \pm 8.4$ & 0.119 \\
\hline Body mass index, $\mathrm{kg} / \mathrm{m}^{2}$ & $25.6 \pm 4.3$ & $25.1 \pm 4.7$ & 0.091 \\
\hline \multicolumn{4}{|l|}{ DM } \\
\hline Insulin-dependent & 74(15.9) & $67(14.4)$ & 0.583 \\
\hline Non-insulin-dependent & $68(14.6)$ & $61(13.1)$ & 0.569 \\
\hline Hypertension & $246(52.8)$ & 237(50.9) & 0.6 \\
\hline Hyperlipemia & $137(29.4)$ & 123(26.4) & 0.342 \\
\hline $\mathrm{GFR}\left(\mathrm{ml} / \mathrm{min} / 1.73 \mathrm{~m}^{2}\right)$ & $81.3 \pm 16.4$ & $80.4 \pm 15.7$ & 0.392 \\
\hline COPD & $38(8.2)$ & $44(9.4)$ & 0.563 \\
\hline \multicolumn{4}{|l|}{ Previous } \\
\hline Cerebal infarction & $24(5.2)$ & $29(6.2)$ & 0.572 \\
\hline Myocardial infarction & $75(16.1)$ & $66(14.2)$ & 0.465 \\
\hline $\mathrm{PCl}$ & $81(17.4)$ & 73(15.7) & 0.537 \\
\hline LVEF & & & 0.33 \\
\hline$>0.50$ & $363(77.9)$ & $375(80.5)$ & \\
\hline $0.30-0.50$ & $98(21.0)$ & $87(18.7)$ & \\
\hline$<0.30$ & $5(1.1)$ & $4(0.9)$ & \\
\hline Extent of CAD & & & 0.187 \\
\hline 1 vessel & $17(3.6)$ & $25(5.4)$ & \\
\hline 2 vessel & $48(10.3)$ & $54(11.6)$ & \\
\hline 3 vessel & $401(86.1)$ & $387(83.0)$ & \\
\hline LM & 142(30.1) & $122(26.2)$ & 0.167 \\
\hline EuroScorell & $2.6 \pm 1.2$ & $2.5 \pm 1.3$ & 0.223 \\
\hline Distal anastomosis & $3.4 \pm 0.9$ & $3.3 \pm 1.1$ & 0.129 \\
\hline LIMA & 438(94.0) & $444(95.3)$ & 0.467 \\
\hline Radial Artery & $72(15.5)$ & $63(13.5)$ & 0.457 \\
\hline CPB time(min) & $78.4 \pm 21.7$ & - & - \\
\hline
\end{tabular}

$D M$ diabetes mellitus, $P C I$ percutaneous coronary intervention, COPD chronic obstructive pulmonary disease, GFR glomerular filtration rate, LVEF left ventricular ejection fraction, $C A D$ coronary artery disease, LIMA left internal mammary artery, $C P B$ cardiopulmonary bypass

in the rate and severity of AKI was found between the two groups. $(\mathrm{u}=0.543, p=0.532)$. (Table 2$)$, (Fig. 1$)$.

\section{Long-term outcomes}

The mean follow-up time was $50.6 \pm 9.5$ months. There were 70 patients died during the follow-up (33 in A group and 37 in B group), and 24 patients were lost to follow-up totally(14 in A group and 10 in B group). (Table 2). Comparing with A group, B group did not have an decreased new onset of dialysis $\left(x^{2}=0.14, p=\right.$ $0.708)$ or mortality $\left(x^{2}=0.099, p=0.753\right)$ during the long-term follow-up(Table 2), (Fig. 2). Comparing with in-hospital non-AKI patients, in-hospital AKI patients 
Table 2 Postoperative outcomes in the matched cohort

\begin{tabular}{|c|c|c|c|}
\hline \multirow[t]{2}{*}{ variable } & \multirow{2}{*}{$\begin{array}{l}\text { A group } \\
(n=466) \text { No. }(\%)\end{array}$} & \multirow{2}{*}{$\begin{array}{l}\text { B group } \\
(n=466) \text { No. }(\%)\end{array}$} & \multirow{2}{*}{$\begin{array}{l}p \\
\text { value }\end{array}$} \\
\hline & & & \\
\hline \multicolumn{4}{|l|}{ In-hospital } \\
\hline Mortality & $11(2.4)$ & $9(1.9)$ & 0.821 \\
\hline $\mathrm{Ml}$ & $19(4.1)$ & $15(3.2)$ & 0.6 \\
\hline Stroke & $11(2.4)$ & $7(1.5)$ & 0.475 \\
\hline Respiratory failure & $20(4.3)$ & $15(3.2)$ & 0.491 \\
\hline Pneumonia & $26(5.6)$ & $21(4.5)$ & 0.549 \\
\hline AKI & 197 & 179 & 0.532 \\
\hline Stage 1 & 139(29.8) & $131(28.1)$ & \\
\hline Stage 2 & $40(8.6)$ & $35(7.5)$ & \\
\hline Stage 3 & $18(3.9)$ & $13(2.8)$ & \\
\hline In-hospital dialysis & $13(2.8)$ & $8(1.7)$ & 0.377 \\
\hline RBC transfusion & $196(42.1)$ & 175(37.6) & 0.181 \\
\hline DSWI & $10(2.1)$ & $7(1.5)$ & 0.624 \\
\hline LCOS & $21(4.5)$ & $25(5.4)$ & 0.650 \\
\hline IABP application & $18(3.9)$ & $19(4.1)$ & 1 \\
\hline \multicolumn{4}{|l|}{ Longer-term } \\
\hline Lost to follow-up & $14(3.1)$ & $10(2.2)$ & 0.535 \\
\hline New onset of dialysis & $5(1.1)$ & $3(0.7)$ & 0.708 \\
\hline Mortality & $33(7.5)$ & $37(8.3)$ & 0.753 \\
\hline
\end{tabular}

$M I$ myocardial infarction, $A K I$ acute kidney injury, $R B C$ red blood cell, $D S W I$ deep sternal wound infection, $L C O S$ low cardiac output syndrome, IABP intraaortic balloon pump were associated with an increased long-term new onset of dialysis $\left(x^{2}=8.153, p=0.004\right)$ and decreased longterm survival ( $\left.x^{2}=6.277, p=0.012\right)$. (Table 3), (Fig. 3). Multivariable logistic regression manifested that the HR for long-term new onset of dialysis and mortality in AKI patients vs. non-AKI patients was 1.83 and 1.31 respectively $(95 \%$ CI $1.12-2.86, p=0.007 ; 95 \%$ CI $1.17-2.58, p=$ 0.015). The HR for long-term new onset of dialysis and mortality in on-pump group vs. off-pump group was 1.07 and 1.11 respectively $(95 \% \mathrm{CI} 1.03-1.23, p=0.661$; 95\%CI 1.09-1.64, $p=0.702$ ). (Table 4).

\section{Discussion}

The principal findings of this single-centre, retrospective PSM study can be summarized as follows. (1) AKI of any severity occurred in $40.3 \%$ of all CABG patients aged older than 70 years, with AKIN stage 1 accounting for most AKI cases(71.8\%). New onset of dialysis was applied in 2.3\% of all patients. (2) Comparing with onpump CABG, off-pump CABG was neither associated with decreased rate or severity of postoperative AKI nor with decreased long-term new onset of dialysis or mortality in such cohort. (3) Postoperative in-hospital AKI increased the rate of new onset of dialysis and decreased the survival rate in long-term follow-up.

PSM analysis provided the opportunity to rule out confusion by providing balanced baseline and procedural characteristics except the application of CPB. Certainly there was no significant difference in other factors, including the experience of surgeons. The univariate factor analysis manifested that the two PSM groups had similar in-hospital mortality and most of morbidities.

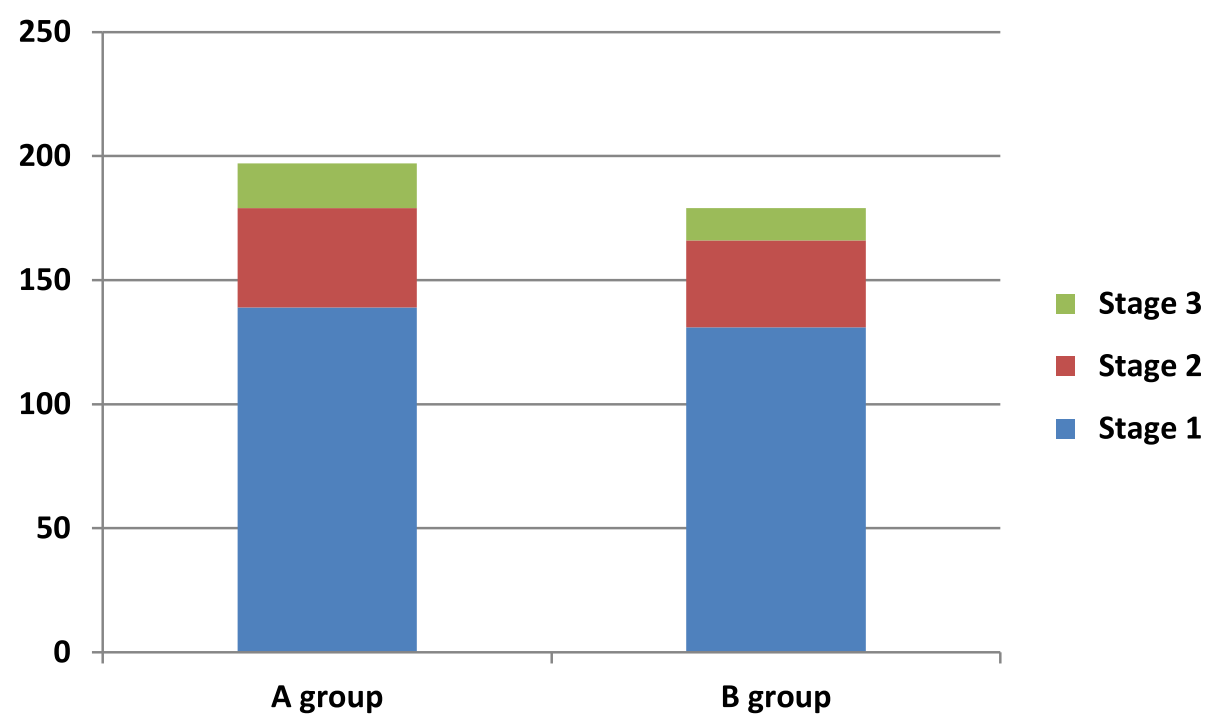

Fig. 1 Acute kidney injury (AKI), as defined and classified according to the criteria proposed by the Acute Kidney Injury Network (AKIN), is shown stratified according to kidney function at baseline (blue $=A K I$, red $=A K I 2$, green $=A K I 3 ; y$-axis = number of patients) 


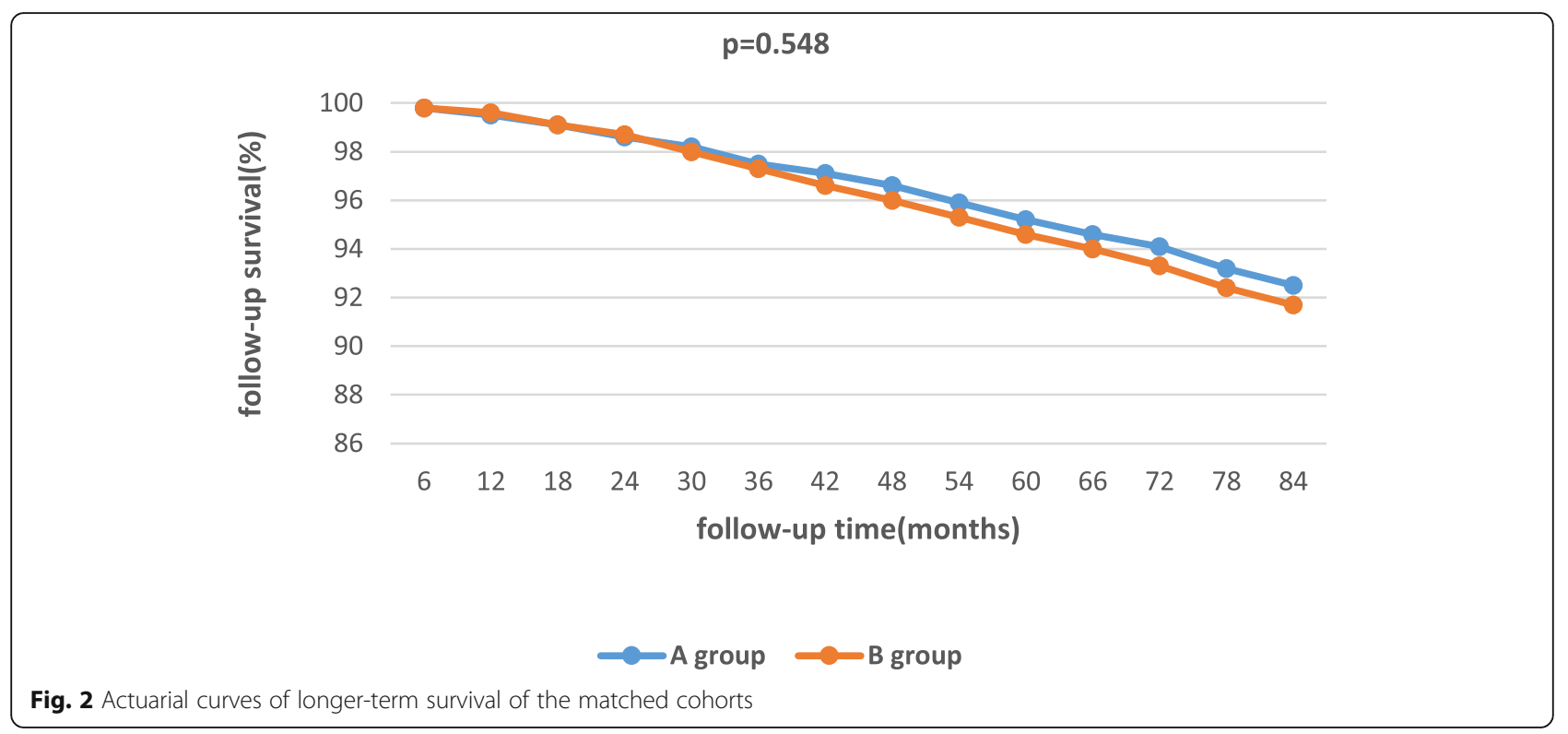

AKI occurs in up to $30 \%$ of patients undergoing CABG, depending on the underlying definition [13]. The rate of new onset of renal dialysis following cardiac surgery ranged from 1 to 6\% [14]. Veterans Affairs Randomized On/Off Bypass (ROOBY) trial showed new renal dialysis within 30 days postoperatively was $0.9 \%$ [15]. Garg et al. performed a detailed analysis evaluating kidney function of the CORONARY patient population, overall $1.2 \%$ of these patients needed new renal dialysis $[16,17]$. In our study, AKI was a common complication that occurred in $40 \%$ of all patients, and $2.3 \%$ needed renal dialysis. The incidence in our study was higher than that reported in the literatures. In addition, the incidence of new renal dialysis for AKI patients was 4.5\% in our study, which was obviously higher than the average. The same result was obtained by Wilko Reents et al., they promoted a study named" The German Off Pump Coronary Artery Bypass Grafting in Elderly Patients (GOPCABE)", which only enrolled patients aged 75 years or older to CABG with or without CPB [18]. It

Table 3 In-hospital and longer-term outcomes in AKI and nonAKI group

\begin{tabular}{llll}
\hline variable & $\begin{array}{l}\text { AKl group } \\
(n=382)\end{array}$ & $\begin{array}{l}\text { Non-AKI group }(\%) \\
(n=550)\end{array}$ & $p$ vo. (\%) \\
\hline $\begin{array}{llll}\text { In-hospital } \\
\text { New onset of dialysis }\end{array}$ & $21(4.5)$ & 0 & 0.000 \\
$\quad$ Mortality & $12(3.1)$ & $8(1.5)$ & 0.129 \\
$\begin{array}{llll}\text { Longer-term } \\
\text { Lost to follow-up }\end{array}$ & $11(2.9)$ & $13(2.4)$ & 0.780 \\
New onset of dialysis & $9(2.4)$ & $1(0.2)$ & 0.004 \\
Mortality & $39(10.5)$ & $31(5.8)$ & 0.012 \\
\hline
\end{tabular}

is therefore reasonable to assume that the relative high rate of AKI and new renal dialysis in our study was mainly due to the high proportion of particularly vulnerable elderly patients with preexisting kidney dysfunction, as was shown in table1, average baseline GFR was only about $81 \mathrm{ml} / \mathrm{min} / 1.73 \mathrm{~m}^{2}$. As is reported that age and preoperative renal dysfunction are both independent risk factors of AKI [19].

CPB still contributes to renal injury due to multiple perturbations in renal physiology and function as mentioned before. Off-pump technique seems to be a logical step toward preventing postoperative AKI. However, the effect of off-pump CABG on kidney function is still discussed controversially in literatures [14, 20]. The largest single randomized trial (CORONARY) found an absolute $4.1 \%$ risk reduction of AKI for off-pump CABG, but the reduction was contributed only by decreased occurrence of AKI stage 1, more severe stages of AKI or new renal dialysis were of no significant differences between the two groups, our center was also one of the collaborators of the CORONARY study [16]. A meta-analysis of 37 randomized controlled trials $(n=3449)$ and 22 riskadjusted observational studies $(n=293,617)$ concluded that the benefit for off-pump CABG was only in the observational studies, but the difference was not significant in the aggregate randomized trials [21].

In this study we also found that compared with onpump CABG, off-pump CABG was not associated with decreased rate or severity of AKI in elderly patients. We speculated the reasons were as follows: (1) The different definitions of AKI used in this study and methodological concerns precluded definitive conclusions from other trials. (2) Average CPB duration(mean time was 78.4 min) was relatively short, which attenuated pump- 


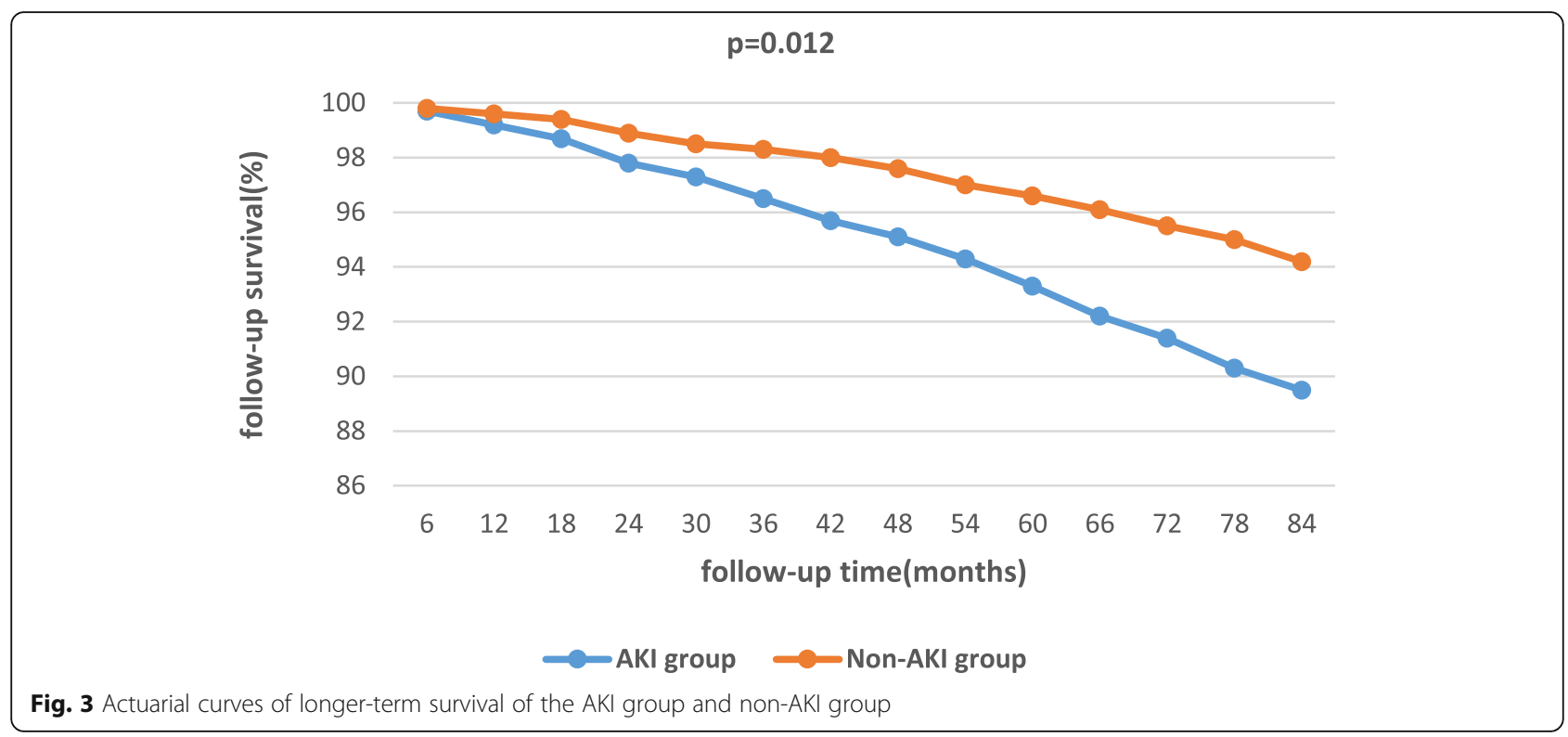

induced hemolysis, thereby releasing hemoglobin and free iron, and injuring the renal tubule [22]. (3) Relative high perfusion pressure was kept to guarantee the renal perfusion, especially in elderly patients undergoing onpump surgery [23]. (4) The inflammatory response did not differ greatly between on-pump and off-pump groups $[24,25]$. (5) When performing the anastomosis of the lateral vessels, transient circulatory failure and global hypoperfusion (renal malperfusion) often occurred during the off-pump surgery. (6) Atheroembolism caused by aortic manipulation(cross and side clamping) is another possible reason of renal impairment, which may occur in both on- and off-pump surgery. (7) Onpump technique provided improved complete revascularization, so it is conducive to the recovery of cardiac function and renal perfusion. (8) There are no active treatments for AKI, and therefore, perioperative preventative strategies seem particularly promising. Keep adequate hydration and avoid the use of diuretics; minimize the use of medications with adverse effects on renal function; keep an optimal hemodynamic status and correct the acid-base or metabolic imbalance. All of the aboved strategies might offset the differences in renal impairment between the two groups.

As expected, the follow-up demonstrated that inhospital AKI patients showed a trend to higher new onset of dialysis $(2.4 \%$ vs $0.2 \%, p=0.004)$ and lower longterm survival $(89.5 \%$ vs $94.2 \%, p=0.012)$ compared with non-AKI patients in this study. Cox regression manifested that postoperative in-hospital AKI was a significant variable related to the new onset of dialysis and long-term mortality, and the HR was 1.83 and 1.31 respectively (95\%CI 1.12-2.86, $p=0.007$; 95\%CI $1.17-2.58$, $p=0.015$ ). This study was consistent with our previous study and some other studies which demonstrated that development of AKI was associated with high shortterm and long-term morbidity and mortality [18, 26]. AKI has been associated with progression to chronic kidney disease(CKD) and dialysis in many reports [27]. CKD and dialysis might exert negative efferts on the long-term survival inevitably especially in elderly patients [28]. Unfortunately, there are no pharmacologic agents known to reduce the risk of AKI or treat established AKI. Therefore, AKI patients after CABG need to

Table 4 Predictors of long-term new onset of dialysis /long-term mortality

\begin{tabular}{llll}
\hline Variable & HR & $95 \% \mathrm{Cl}$ & $p$ value \\
\hline In-hospital AKI vs. non-AKI & $1.83 / 1.31$ & $1.12-2.86 / 1.17-2.58$ & $0.007 / 0.015$ \\
Age (per y) & $1.25 / 1.79$ & $1.13-1.72 / 1.27-2.02$ & $0.003 /<0.0001$ \\
Gender (Female vs. male) & $1.24 / 1.47$ & $1.03-1.55 / 1.03-2.02$ & $0.21 / 0.19$ \\
DM & $1.39 / 1.41$ & $1.02-1.88 / 1.09-1.53$ & $0.012 / 0.035$ \\
LVEF<0.50 & $1.43 / 1.98$ & $1.02-2.27 / 1.05-2.26$ & $0.025 / 0.003$ \\
$\quad$ On-pump vs. off-pump & $1.07 / 1.11$ & $1.03-1.23 / 1.09-1.64$ & $0.661 / 0.702$ \\
IABP application & $2.32 / 2.06$ & $1.11-2.87 / 1.05-2.10$ & $0.001 /<0.0001$ \\
\hline
\end{tabular}


strengthen the follow-up of nephropathy, more strictly management of the risk factors of coronary artery disease postoperatively.

\section{Limitations}

Firstly, a retrospective, non-randomized single-centre analysis over a long period of time and with different surgeon's procedures on patients undergoing CABG is subjected to the effects of selection bias, for example, low percentage of female patients and high percentage of patients with good ventricular function, baseline GFR was $>80 \%$. Although PSM is implemented, a prospective, multi-centre study involving larger sample size is needed. Secondly, the GFR was derived by using the MDRD formula, which was not designed for determining GFR. Thirdly, the initial RIFLE criteria do not include the creatinine increase within $48 \mathrm{~h}$ for defining the mildest form of AKI, whereas the RIFLE categories injury and loss are similar to AKIN stage 2 and 3, respectively. AKI defined according to the RIFLE criteria may therefore avoid an iatrogenic hemodilution but may miss more subtle changes of kidney function [18]. Finally, onpump CABG is usually associated with more grafts and more transfusions, but after PSM with off-pump group, some on-pump cases have to be excluded.

\section{Conclusions}

In summary, this analysis revealed that AKI was common in elderly patients receiving CABG, but deterioration of dialysis was relatively scarce. We failed to observe better kidney function with off-pump vs. onpump in terms of postoperative rate or severity of AKI in elderly patients. In-hospital AKI increased the rate of new onset of dialysis and decreased the survival rate in elderly patients in the longer-term.

\section{Abbreviations \\ PSM: Propensity score matching; CPB: Cardiopulmonary bypass; AKI: Acute kidney injury; CABG: Coronary artery bypass grafting; AKIN: Acute kidney injury network; GFR: Glomerular filtration rate; PS: Propensity score; BMI: Body mass index; DM: Diabetes mellitus; COPD: Chronic obstructive pulmonary disease; MI: Myocardial infarction; PCl: Percutaneous coronary intervention; LVEF: Left ventricular ejection fraction; LIMA: Left internal mammary artery; DSWI: Deep sternal wound infection; LCOS: Low cardiac output syndrome; IABP: Intra-aortic balloon pump; CKD: Chronic kidney disease}

\section{Acknowledgements}

None.

\section{Authors' contributions}

RW and XC conceived of the study, and participated in its design and coordination and helped to draft the manuscript. RW and XW participated in the design of the study and drafted the manuscript. WC, YFZ and LPL carried out the data collection and statistical analysis. All authors read and approved the final manuscript, and agreed for publication.

\section{Funding}

This work was supported by National Natural Science Foundation of China(No.81870193); Jiangsu Provincial Special Program of Medical Science(BE2017610); The Young Program of National Natural Science
Foundation of China (No.81700415); The Project of Invigorating Health Care through Science, Technology and Education-- Jiangsu Provincial Medical Youth Talent.

\section{Availability of data and materials}

All data and material are available by contactingwr1582@163.com

\section{Ethics approval and consent to participate}

This study was approved by The Ethics Committee of Nanjing First Hospital. All patients agreed that their stored material was enclosed and that their clinical data were anonymously used for statistical analysis.

\section{Consent for publication}

Written informed consent was obtained from the patient before publication.

\section{Competing interests}

All of the authors declare that they have no competing interests.

\section{Author details}

'Department of Cardiovascular Surgery, Nanjing First Hospital, Nanjing Medical University, Nanjing, 68 Changle Rd, Nanjing 210006, People's Republic of China. ${ }^{2}$ Department of Laboratory Medicine, Nanjing Drum Tower Hospital, Nanjing University Medical School, Nanjing, 321 Zhongshan Rd, Nanjing 210008, People's Republic of China.

Received: 11 March 2020 Accepted: 14 July 2020

Published online: 24 July 2020

\section{References}

1. Kellum JA, Lameire N. KDIGO AKI Guideline Work Group. Diagnosis, evaluation, and management of acute kidney injury: a KDIGO summary (Part 1). Crit Care. 2013;17(1):204. https://doi.org/10.1186/cc11454.

2. Rosner MH, Okusa MD. Acute kidney injury associated with cardiac surgery. Clin J Am Soc Nephrol. 2006;1:19-32.

3. Ronco C, Bellomo R, Kellum JA. Acute kidney injury. Lancet. 2019; 394(10212):1949-64.

4. Coca SG, Yusuf B, Shlipak MG, et al. Longterm risk of mortality and other adverse outcomes after acute kidney injury: a systematic review and metaanalysis. Am J Kidney Dis. 2009;53:961-73.

5. Lannemyr L, Bragadottir $G$, Krumbholz $V$, et al. Effects of cardiopulmonary bypass on renal perfusion, filtration, and oxygenation in patients undergoing cardiac surgery. Anesthesiology. 2017;126(2):205-13.

6. Pickering JW, James MT, Palmer SC. Acute kidney injury and prognosis after cardiopulmonary bypass: a meta-analysis of cohort studies. Am J Kidney Dis. 2015;65(2):283-93

7. Kirmani BH, Holmes MV, Muir AD. Long-term survival and freedom from reintervention after off-pump coronary artery bypass grafting: a propensitymatched study. Circulation. 2016:134:1209-20.

8. Zakkar M, Angelini GD. Preoperative renal impairment and off-pump coronary artery bypass grafting: the jury is still out. J Thorac Cardiovasc Surg. 2018;156:974-5.

9. Filardo G, Hamman BL, da Graca B, et al. Efficacy and effectiveness of onversus off-pump coronary artery bypass grafting: a meta-analysis of mortality and survival. J Thorac Cardiovasc Surg. 2018;155:172-9 e5.

10. Lamy A, Devereaux PJ, Prabhakaran D, et al. Five-year outcomes after offpump or on-pump coronary-artery bypass grafting. N Engl J Med. 2016;375: 2359-68.

11. KJOQI Clinical Practice Guidelines for Chronic Kidney Disease: evaluation, classification, and stratification. Part 4: definition and classification of stages of chronic kidney disease. Am J Kidney Dis. 2002;39(2 Suppl 1):S1-266.

12. Kara I, Yildirim F, Kayacan E, et al. Importance of RIFLE (Risk, Injury, Failure, Loss, and End-Stage Renal Failure) and AKIN (Acute Kidney Injury Network) in Hemodialysis Initiation and Intensive Care Unit Mortality. Iran J Med Sci. 2017:42(4):397-403.

13. Loef BG, Epema AH, Smilde TD, Henning RH, Ebels T, Navis G, Stegemann C. Immediate postoperative renal function deterioration in cardiac surgical patients predicts in-hospital mortality and long-term survival. J Am Soc Nephrol. 2005;16:195-200.

14. Mariscalco G, Lorusso R, Dominici C, Renzulli A, Sala A. Acute kidney injury: a relevant complication after cardiac surgery. Ann Thorac Surg. 2011;92:1539-47. 
15. Shroyer AL, Grover FL, Hattler B, et al. For the Veterans Affairs Randomized On/Off Bypass (ROOBY) Study Group. On-pump versus off-pump coronaryartery bypass surgery. N Engl J Med. 2009;361:1827-37.

16. Lamy A, Devereaux PJ, Prabhakaran D, et al. For the CORONARY investigators. Off-pump or on-pump coronary artery bypass grafting at 30 days. N Engl J Med. 2012;366:1489-97.

17. Garg AX, Devereaux PJ, Yusuf S, et al. Coronary Artery Bypass Grafting Surgery Off- or On-pump Revascularisation Study (CORONARY): kidney substudy analytic protocol of an international randomised controlled trial. BMJ Open. 2012;2:e001080

18. Reents W, Hilker M, Borgermann J, et al. Acute kidney injury after on-pump or off-pump coronary artery bypass grafting in elderly patients. Ann Thorac Surg. 2014;98:9-15.

19. Helgadottir S, Sigurdsson Ml, Palsson R, et al. Renal recovery and long-term survival following acute kidney injury after coronary artery surgery: a nationwide study. Acta Anaesthesiol Scand. 2016;60(9):1230-40

20. Seabra VF, Alobaidi S, Balk EM, et al. Off-pump coronary artery bypass surgery and acute kidney injury: a metaanalysis of randomized controlled trials. Clin J Am Soc Nephrol. 2010;5:1734-44.

21. Wijeysundera DN, Beattie WS, Djaiani G, et al. Off-pump coronary artery surgery for reducing mortality and morbidity: meta-analysis of randomized and observational studies. J Am Coll Cardiol. 2005:46:872-82.

22. Vermeulen Windsant IC, Snoeijs MG, Hanssen SJ, et al. Hemolysis is associated with acute kidney injury during major aortic surgery. Kidney Int. 2010;77:913-20.

23. Sgouralis I, Evans RG, Gardiner BS, et al. Renal hemodynamics, function, and oxygenation during cardiac surgery performed on cardiopulmonary bypass: a modeling study. Physiol Rep. 2015;3(1):1-14.

24. Biglioli P, Cannata A, Alamanni F, et al. Biological effects of off-pump versus on-pump coronary artery surgery: focus on inflammation, haemostasis and oxidative stress. Eur J Cardiothorac Surg. 2003;24:260-9.

25. Wehlin L, Vedin J, Vaage J, Lundahl J. Activation of complement and leukocyte receptors during on- and off pump coronary artery bypass surgery. Eur J Cardiothorac Surg. 2004;25:35-42.

26. Wang $X$, Zhu Y, Chen W, et al. The impact of mild renal dysfunction on isolated cardiopulmonary coronary artery bypass grafting: a retrospective propensity score matching analysis. J Cardiothorac Surg. 2019;14(1):191. https://doi.org/10.1186/s13019-019-0998-4

27. Chawla LS, Eggers PW, Star RA, et al. Acute kidney injury and chronic kidney disease as interconnected syndromes. N Engl J Med. 2014;371:58-66.

28. Yokota LG, Sampaio BM, Rocha EP, et al. Acute kidney injury in elderly patients: narrative review on incidence, risk factors, and mortality. Int J Nephrol Renovasc Dis. 2018;14(11):217-24

\section{Publisher's Note}

Springer Nature remains neutral with regard to jurisdictional claims in published maps and institutional affiliations.

Ready to submit your research? Choose BMC and benefit from:

- fast, convenient online submission

- thorough peer review by experienced researchers in your field

- rapid publication on acceptance

- support for research data, including large and complex data types

- gold Open Access which fosters wider collaboration and increased citations

- maximum visibility for your research: over $100 \mathrm{M}$ website views per year

At $\mathrm{BMC}$, research is always in progress.

Learn more biomedcentral.com/submissions 